\title{
Student Learning in an Accelerated Introductory Biology Course Is Significantly Enhanced by a Flipped- Learning Environment
}

Ana Maria Barral,* Veronica C. Ardi-Pastores, and Rachel E. Simmons

Department of Mathematics and Natural Sciences, College of Letters and Sciences, National University, San Diego, CA 92037

\begin{abstract}
A flipped-classroom environment generally strives to create more in-class time for activities that enhance student learning, while shifting some content delivery to outside the classroom through the use of short didactic videos. We compared a flipped-classroom setting with the traditional ("control") setting for an accelerated lower-division general biology course. Student self-reporting and video analytics functions showed ample and variable video viewing among individual students. Student learning was evaluated through quizzes administered after a set of concepts were covered (post 1) and at the end of the course (post 2). Students in the flipped sections had significantly higher quiz scores than students in the control sections for both post 1 and post 2 . Analyses of variance analyzing the effect of and interactions between type of instruction, in-class activities, time, and Bloom's level of the quiz questions found significant differences in the overall model and all the factors, except for the presence and level of activities. Significant differences between students in the flipped and control sections were observed for low-level Bloom's questions only. Thus, the positive effect of the flipped-classroom approach on student learning may be due to improvements in recall of basic concepts and a better understanding of biology vocabulary in their first biology course.
\end{abstract}

\section{INTRODUCTION}

Two current major concerns in U.S. higher education are a decrease in the number of graduates in science, technology, engineering, and mathematics (STEM) disciplines and underrepresentation of minorities among such graduates (President's Council of Advisors on Science and Technology [PCAST], 2012; Chen and Soldner, 2013). STEM educators face the challenging task of not only rethinking their teaching approaches to ensure students persist and succeed in their disciplines, but also doing so in a way that promotes diversity (McGlynn, 2017). As students bring their unique backgrounds and experiences to the classroom, the onus is on the instructors to address "how to select the right tools for the job, how to use the tools, and what latitude there is for using a range of tools" (Dolan, 2015, p. 1).

In the past decade, the biology education research community has identified a number of evidence-based instructional practices (Freeman et al., 2007, 2011; Handelsman et al., 2007; Bradforth et al., 2015; Eddy et al., 2015; James and Singer, 2016; Jordt et al., 2017). Overall, hands-on, inquiry-based, and active-learning approaches seem to have a positive impact on student learning and engagement (PCAST, 2012; Freeman et al., 2014; Dirks and Knight, 2016; Ballen et al., 2017). Moreover, it has been described that active-learning approaches and more structured teaching disproportionately benefit certain demographic populations such as Blacks/ African Americans, Hispanics, and first-generation college students (Freeman et al., 2007; Haak et al., 2011; Eddy and Hogan, 2014). National calls such as the Vision and
Jennifer Knight, Monitoring Editor Submitted Jul 17, 2017; Revised May 1, 2018 Accepted May 17, 2018

CBE Life Sci Educ September 1, 2018 17:ar38 DOI:10.1187/cbe.17-07-0129

*Address correspondence to: Ana Maria Barral (abarral(anu.edu).

(c) 2018 A. M. Barral et al. CBE-Life Sciences Education (c) 2018 The American Society for Cell Biology. This article is distributed by The American Society for Cell Biology under license from the author(s). It is available to the public under an Attribution-Noncommercial-Share Alike 3.0 Unported Creative Commons License (http://creativecommons.org/licenses/ by-nc-sa/3.0).

"ASCB®" and "The American Society for Cell Biology $\circledR^{\prime \prime}$ are registered trademarks of The American Society for Cell Biology. 
Change (VC) reports (American Association for Advancement of Science [AAAS], 2011, 2015) and Engage to Excel (PCAST, 2012) advocate for the introduction of such practices to increase student engagement and learning.

Among the growing volume of research dedicated to science education, studies tend to be conducted by traditional institutions with traditional students, despite nontraditional students currently representing the majority of the student population (Radford et al., 2015). Nontraditional students are characterized as older, often having jobs, and having higher minority representation, while traditional students tend to be full-time students who are 18-24 years of age (Choy, 2002). Within biology education in general, one review found that only $3 \%$ of articles published explicitly included community colleges (Schinske et al., 2017). For active-learning modalities specifically, no nontraditional institutions or community colleges were represented in an extensive review (Freeman et al., 2014). A recent study that surveyed instructional practices via class observations in seven STEM disciplines focused exclusively on 24 doctorate-granting institutions and one primarily undergraduate institution (a state university; Stains et al., 2018). This underrepresentation is particularly curious, as active-learning approaches have been shown to decrease the achievement gap of underrepresented minority (URM) students (Haak et al., 2011; Estrada et al., 2016; Ballen et al., 2017). The growing population of nontraditional students in nontraditional institutions highlights the need to expand education research in the field.

One effective strategy to maximize active-learning approaches in the classroom and provide students with individualized support is "flipping" the classroom. The flipped classroom is usually associated with providing course materials, frequently in the form of video-based lectures for students to engage outside the classroom, which enables in-class time to be repurposed for student-centered collaborative learning activities (Strayer, 2011; Hamdan et al., 2013). Students in a flipped classroom therefore have the benefit of being able to access material traditionally disseminated in lecture in an unlimited capacity.

It is important to note that just providing videos for students to watch outside the classroom does not represent the pedagogical approach of flipped learning, in which "direct instruction moves from the group learning space to the individual learning space, and the resulting group space is transformed into a dynamic, interactive learning environment where the educator guides students as they apply concepts and engage creatively in the subject matter" (Flipped Learning Network, 2014). The pillars of flipped learning can be explained using the letters F-LI-P: Flexible environment, Learner-centered approach, Intentional content, and Professional educators (Flipped Learning Network, 2014). An optimal flipped-learning environment supports and engages students by increasing both extrinsic and intrinsic motivation and managing the cognitive load more effectively (Abeysekera and Dawson, 2014). In the field of biology, the flipped-classroom approach has been shown by some authors to enhance student metacognition and collaborative learning (Van Vliet et al., 2015) and to improve student outcomes (Gross et al., 2015) among other positive results, while others reported no difference between the control and flipped sections (Yong et al., 2015; Adams et al., 2016; Arnott and Planey, 2017).
The present study addresses the implementation and assessment of a flipped-learning approach in an intensive course setting with a nontraditional student population. Nontraditional students and millennials prefer flexible formats that allow them to juggle multiple responsibilities (Aslanian, 2017), which may explain the popularity of intensive (accelerated) course formats. In such settings, students complete their courses in a shorter time frame by attending more frequent and longer class times. Studies have shown that accelerated programs can be as successful and rigorous as their traditional counterparts (Wlodkowski and Kasworm, 2003; Baun, 2008). Moreover, features of high-quality intensive courses overlap with the pillars of FLIP, including instructor characteristics and active learning in the classroom (Scott, 2003).

National University (NU), a private, nonprofit, comprehensive university, serves a primarily nontraditional student population, with an average student age of 32 and a high representation of minorities, including 10\% African Americans, 10\% Asians, and 28\% Hispanics (College Board, 2017). The high proportion of Hispanic students qualifies NU as a Hispanic-serving institution (Hispanic Association of Colleges and Universities-HACU, n.d.). NU's accelerated course format consists of 45 contact hours provided through 10 class sessions in a 4-week period. Students take only one course at a time. The 4.5-hour class time lends itself to in-class activities and multimedia content to enhance the lecture content.

The authors' goal was to establish a flipped-classroom design together with a set of ungraded in-class activities in a lower-division undergraduate biology course. The activities were intended to reinforce key concepts and support acquisition of higher-level learning. This study examined the effectiveness of the flipped-classroom approach in an accelerated setting in comparison with the more traditional, passive lecture pedagogy. Our hypotheses were that 1) students in the flipped sections would score better than students in the control sections in a set of quizzes targeting specific biology concepts, 2) their scores would remain higher with time, and 3) implementation of ungraded in-class activities would positively affect the scores of student quizzes.

\section{METHODS}

\section{Human Subjects Protocol}

This project was exempted by the NU Institutional Review Board (document 704990-5).

\section{Course}

The BIO161 course is the first in a series of three courses corresponding to the majors' general biology curriculum. The course is a requirement for the bachelor's of science (BS) in biology, the BS in clinical lab science, and the BS radiation therapy programs. BIO161 covers basic concepts of biochemistry, cell biology, and genetics. The official learning objectives (LOs) of the course address topics related to biomolecules, cell structure, metabolic processes, genetics, and molecular biology (Supplemental Table 1S). The course is taught in an accelerated format of 4 weeks, with 45 hours of in-class time (corresponding to 10 sessions of 4.5 hours, twice a week in addition to two Saturdays). Students do not take any other courses during this time. 
TABLE 1. Student demographics in the flipped and control sections $^{\text {a }}$

\begin{tabular}{lcc}
\hline Characteristics & $\begin{array}{r}\text { Flipped } \\
(N=\mathbf{8 8})\end{array}$ & $\begin{array}{r}\text { Control } \\
(N=54)\end{array}$ \\
\hline Female & 55.68 & 55.56 \\
Male & 43.18 & 44.44 \\
Ethnicity & & \\
American Indian/Alaskan Native & 1.14 & 1.85 \\
Asian & 15.91 & 9.26 \\
Black or African American & 7.95 & 9.26 \\
Hispanic & 26.14 & 27.78 \\
Native Hawaiian/Pacific Islander & 0 & 1.85 \\
Ethnicity unknown & 7.95 & 5.56 \\
Two or more races & 5.68 & 3.70 \\
White & 34.09 & 40.74 \\
Age groups & & \\
19-24 & 10.23 & 14.81 \\
25-34 & 70.45 & 57.41 \\
35+ & 19.32 & 27.78 \\
\hline
\end{tabular}

${ }^{\mathrm{a} N u m b e r s ~ r e p r e s e n t ~ p e r c e n t ~ o f ~ t o t a l ~ p e r ~ g r o u p . ~ T h e r e ~ w e r e ~ n o ~ s i g n i f i c a n t ~ d i f f e r-~}$ ences between the flipped and control populations using the chi-square test.

\section{Study Population}

Between January 2015 and April 2017, general biology students were taught in either a flipped format (five sections, total $N=88$ ) or a traditional lecture ("control") format (three sections, total $N=55$ ). Students were not aware beforehand of the format of the section. Sections were taught on three different campuses and scheduled with at least 6 months between sections on the same campus to minimize the possibility that students might exchange materials or quiz questions. In this work, we report data from students who completed both the post 1 and post 2 quizzes, resulting in a final $N=46$ for the flipped section and $N=38$ for the control section. Student demographic and grade point average (GPA) data were collected anonymously through the university's Office of Institutional Research. Section sizes ranged between 9 and 21 students.

Student demographic and GPA data are shown in Table 1. A chi-square test did not reveal significant differences between the flipped and the control populations regarding gender, age, or ethnicity (unpublished data).

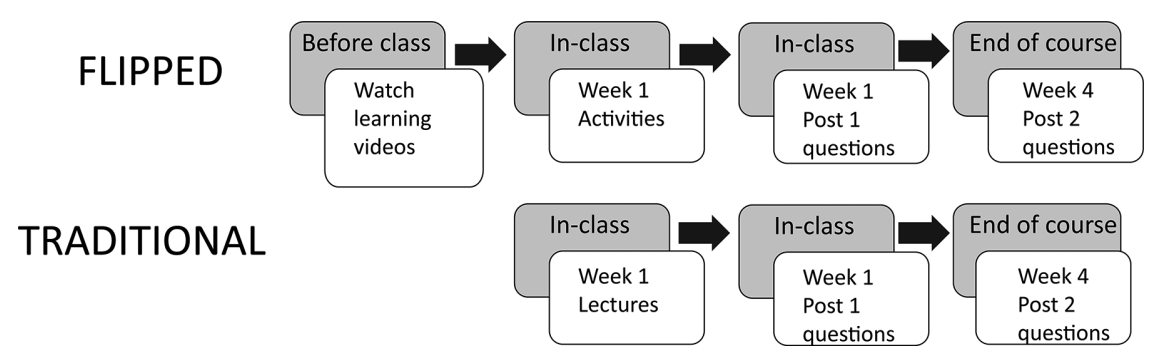

FIGURE 1. General designs of the flipped versus control (traditional) sections. In the flipped sections, students watched the learning videos before coming to class, where they engaged in active learning, while students in the control sections had only lectures in class. Both sections received the same quiz questions at the end of first week of class (post 1) and at the end of the course (post 2).

\section{Course Design}

The general designs of the control and flipped sections are summarized in Figure 1. Both types of courses used the same textbook, covered the same chapters, and had the same learning outcomes. A total of five instructors were involved in the study: two of the study authors (A.M.B. and V.C.A.) taught the flipped sections, while three other instructors taught the control sections. All instructors were comfortable with the material, with teaching experience at the university ranging from 8 to10 years.

In the flipped sections, students had the opportunity to review biology concepts by watching prerecorded videos before attending class (see Recording and Deployment of Lectures section). The flipped design also included short lectures ( $\sim 15$ minutes) to focus on more difficult concepts, and the remaining time was spent engaging in active-learning exercises such as simple experiments and completion of worksheets in small groups, pairs, or individually (see Activities section). In the control sections, students received lectures in class. Instructors of the control sections did not use prerecorded videos or require students to watch any videos before attending class. All control instructors did incorporate watching videos during class time, and one instructor incorporated a group activity related to mitosis (corresponding to LO4, which was not examined in this study). No other active-learning activities were conducted in the control sections.

\section{Recording and Deployment of Lectures}

The instructors teaching the flipped sections recorded short (max. 15-minute) screencasts using Camtasia software (Techsmith, Okemos, MI). Annotations were added using the Doceri program (SP controls, San Francisco, CA) from an iPad screen mirrored on the computer. The recordings were exported to mp4 format, and uploaded to the university's Kaltura Mediaspace video portal (Kaltura, New York, NY), from which they were embedded in the course Blackboard $\mathrm{Bb}$ ) shell. The total number of views was monitored through the Kaltura analytics function. The number of views per student were collected through student self-reporting, and in some cases by using the statistics-tracking feature of $\mathrm{Bb}$.

\section{Assessment}

Two course-level LOs were assessed in this study: 1) describe fundamental concepts in chemistry and biochemistry, including the properties of water, important organic molecules, and acids and bases; and 2) explain cell structure and function and the difference between prokaryotes and eukaryotes. LOs were assessed using questions evaluating different skills per Bloom's taxonomy of learning (Anderson et al., 2001). Three instructors independently scored the questions based on the Blooming Biology tool (Crowe et al., 2008), and questions were assigned low, medium, or high Bloom's levels by consensus. Questions were also aligned to the in-class activities students completed in the flipped sections (see Activities section). All the quiz questions, their Bloom's levels, and their associated 
TABLE 2. In-class activities used in the flipped sections, their scores and alignment to quiz questions, and the Bloom's levels of the quiz questions

\begin{tabular}{llcr}
\hline LO & \multicolumn{1}{c}{ Activity name } & Activity level (score) ${ }^{\text {a }}$ & Bloom's level of mapped quiz question \\
\hline 1 & pH activity & Low (5) & Low \\
1 & Molecular models to review functional groups and biomolecules & High (12) & High \\
2 & Cell structures sheet & Low (4) & Medium \\
2 & Organelle function sheet & Low (4) & Medium \\
2 & Dialysis exercise & High (12) & High \\
\hline
\end{tabular}

activity scores were based on the factors described in Supplemental Table 3S.

activities are shown in Supplemental Figure 1S. Nine of the 15 quiz questions had associated in-class activities.

Flipped and control sections were administered identical questions at two time points. Post 1 quizzes were administered at the end of week 1 of the class for both the flipped and control sections (Figure 1). In the flipped sections, students had lecture videos and in-class learning activities available to them before taking the post 1 quiz, while in the control sections, students completed the post 1 quiz after only in-class lectures. Post 2 quizzes contained the same questions as post 1 , and were administered at the end of week 4 of the course in both the control and flipped sections. Week 4 is the last week of these accelerated biology courses. While post 1 questions were part of required (graded) assignments, post 2 questions were administered as a voluntary set.

\section{Activities}

Ungraded in-class activities were chosen to address major biological concepts throughout the course. Table 2 shows the activities used in the flipped sections that aligned to the quiz questions addressing LO1 and LO2. Brief descriptions of all in-class activities can be found in Supplemental Table 2S. Supplemental Table 3S shows the rubric developed to rank the activities based on factors that have been described as having a high impact on learning (D'Avanzo, 2013; Shaffer et al., 2014; AAAS, 2015). Activities were scored and averaged by three independent instructors and classified as low, medium, and high level. The activities associated to the concepts assessed in the quiz had either a high $(\geq 10)$ or low $(\leq 5)$ level. Medium-level activities, while used in the flipped sections, were not aligned with quiz questions and were therefore excluded from the analysis.

\section{Statistical Analysis}

Student demographic data for the flipped and control sections were compared using the chi-square test.

\section{A. Total number of views per topic}

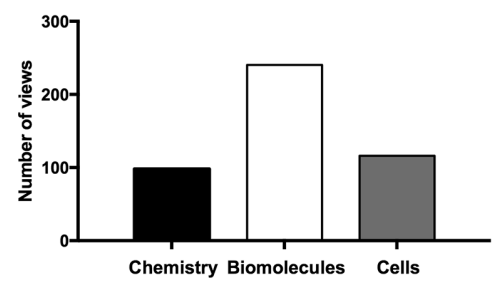

FIGURE 2. (A) Total number of video views per major topics according to the Kaltura analytics function of the flipped sections, reflecting the study period. (B) Student self-reports of the number of times they reviewed the flipped-classroom videos $(N=52)$.
Because our data set contained both paired (two measures on the same student) and unpaired (control vs. flipped) data, we used repeated-measures models to simultaneously test for effects over time and effects from other variables. Pairwise comparisons of flipped and control sections were also tested using Student's and paired $t$ tests.

To assess the effect of different variables (activity levels associated with questions and the Bloom's level of questions), we calculated the Akaike information criterion (AIC) for each set of parameters to determine the best model. A repeated-measures analysis of variance (ANOVA) was then performed on the matched student data (percent of correct answers) to map the effect of treatment (type of instruction), time, and Bloom's level on student scores. For these analyses, JMP software was used (SAS Institute, Cary, NC). Graphs were generated using Prism 7 (GraphPad Software, La Jolla, CA).

\section{RESULTS}

\section{Video Watching Varied per Student and Topic}

Figure 2A shows the total number of views grouped by major biology topics. Most views were dedicated to biomolecules (LO1), followed by cells (LO2), and finally basic chemical concepts (LO1). Ninety-four percent of the students self-reported that they watched the videos, with $10 \%$ reporting that they watched each video more than five times (Figure 2B). Through the statistics-tracking feature of $\mathrm{Bb}$, view data for individual students were obtained. Number of total video views per student per course ranged from 0 to more than 100, with some students viewing individual videos up to 15 times (unpublished data).

\section{Students in Flipped Sections Answered More Questions Correctly Than Students in Control Sections}

Students in both the control and flipped sections completed a set of questions during the first and last week of their courses (post 1 and post 2, respectively, Supplemental Figure 1S). When the percent of correct answers was compared, an independent-samples $t$ test indicated that scores were significantly higher for students in the flipped sections compared with students in the control sections both in post $1(\mathrm{M}=61.5$ and $45, \mathrm{SD}=17.4$ and 16.1 for flipped and control sections, respectively; $t(81)=-4.54, p<0.001, d=$ $0.97)$ and post $2(\mathrm{M}=66.2$ and $54.9, \mathrm{SD}=$ 18.2 and 20.5 for flipped and control, respectively; $t(75)=-3.11, p=0.017, d=$ 0.51 ; Figure 3 ). There was no significant 


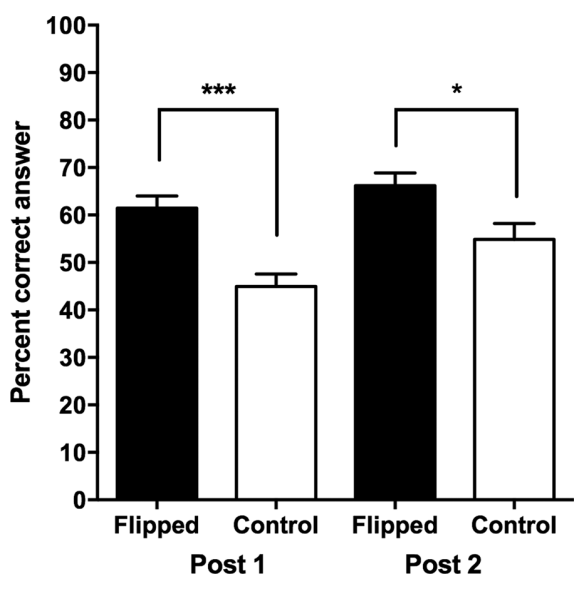

FIGURE 3. Percent of correct answers to the question set in the flipped and control sections at the beginning (post 1 ) and the end (post 2) of class. Post 1 was administered after the concepts were taught (via either flipped methodology or control lecture approach). Significant differences were observed between students in the flipped $(N=46)$ and control $(N=38)$ sections by $t$ tests $(p<0.001$ and $p=0.017$ for post 1 and post 2 , respectively).

difference between post 1 and post 2 scores for the flipped population (paired $t$ test, unpublished data).

When the percent of correct responses was compared by LO, the statistical significance between flipped and control sections remained (Figure 4, A and B). For LO1 at post 1, students in the flipped sections performed significantly better $(\mathrm{M}=61.37$ and 45.34, SD = 19.85 and 20.81 for flipped and control sections, respectively; $t(82)=3.60, d=0.789, p<0.001$ ), and the difference remained significant at post $2(\mathrm{M}=67.5$ and 52.18, $\mathrm{SD}=20.35$ and 21.73, respectively; $t(82)=3.33, d=0.723, p=$ $0.001)$. For LO2, the difference was significant for post 1 only $(\mathrm{M}=61.96$ and $43.42, \mathrm{SD}=24.57$ and 25.79 , respectively; $t(82)=3.37, d=0.736, p=0.001)$, because control students' LO2 scores improved significantly from post 1 to post $2(\mathrm{M}=$ 43.42 and $62.5, S D=25.79$ and 30.62 , respectively; $t(37)=3.5$, $d=-0.674, p=0.001)$.

\section{Students in Flipped Instruction Performed Significantly Better Only on Low-Level Bloom's Questions}

To further assess the factors contributing to higher scores in the flipped sections, we used a multivariate approach to analyze the data in more detail. Based on AIC scores for both post 1 and post 2 regressions, the best-fit model was one that separated student scores by the Bloom's level of the question and type of instruction, as well as interactions between these variables. The level of activity associated with each question did not significantly enhance the fit of the model.

When analyzing student scores per Bloom's level of the questions, not unexpectedly, the lowest scores corresponded to the highest-level Bloom's questions for both flipped and control sections (35.8 and $30.3 \%$ at post 1 , and 46.4 and $39 \%$ at post 2 for flipped and control, respectively). Interestingly, the highest scores corresponded to the medium-level Bloom's questions for students in both flipped and control sections, though these were not significantly higher than those for lowlevel Bloom's questions. Students in flipped sections performed significantly better on low-level Bloom's questions in post $1(\mathrm{M}=67.9$ and $39.3, \mathrm{SD}=0.243$ and 0.269 , respectively, $t(75)=-5.29, p<0.001, d=1.23)$ and in post $2(\mathrm{M}=70.1$ and 54.9 and $\mathrm{SD}=0.279$ and 0.263 , respectively, $t(80)=-3.466$, $p=0.0008, d=0.760$ ). For medium-level Bloom's questions, only in post 1 did students in flipped sections perform significantly better than students in control sections $(\mathrm{M}=71.1$ and $55.7, \mathrm{SD}=0.228$ and 0.237 , respectively, $t(78)=-2.44, p=$ $0.017, d=0.537)$. There was no significant difference in highlevel Bloom's questions at either time point. At each level, students in the flipped sections scored higher than students in the control sections, although the latter group's scores improved with time (Figure 5).
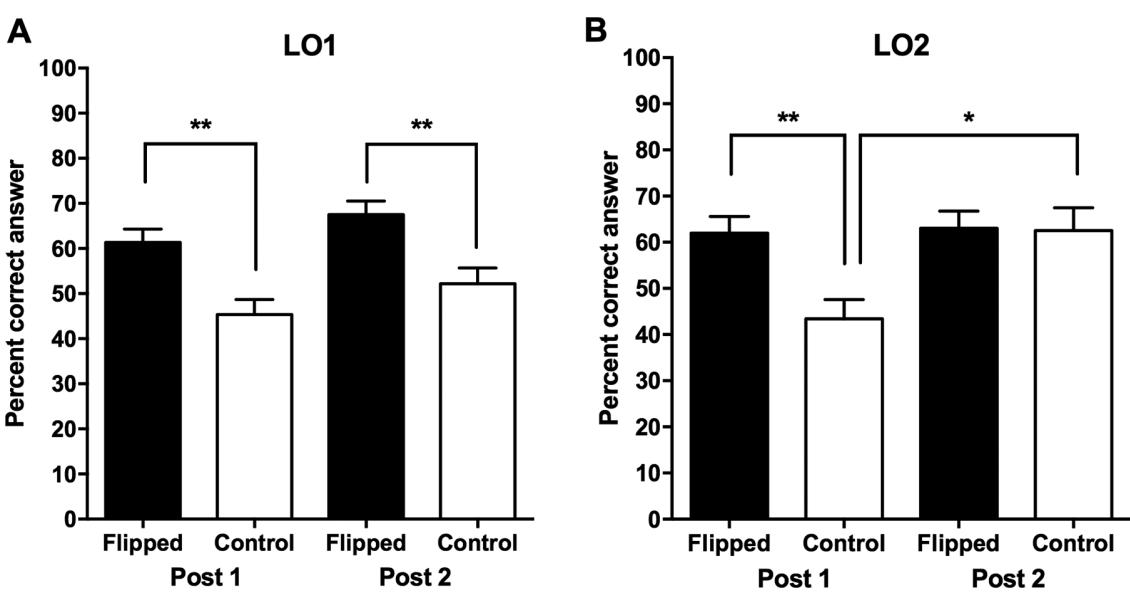

FIGURE 4. Percent correct answers based on learning outcomes (LOs) for post 1 and post 2 (flipped, $N=46$; control, $N=38$ ). (A) LO1 significant differences were observed between students in the flipped and control sections by $t$ tests $(p<0.001$ and $p=0.001$ for post 1 and post 2, respectively). (B) LO2 significant differences were observed between students in the flipped and control sections by $t$ tests for post $1(p=0.001)$ but not post 2 . LO2 scores of students in the control sections improved significantly from post 1 to post 2 $(p=0.001)$.
Repeated-measures ANOVA was used to discern the effect and interactions of factors such as type of instruction, time, and Bloom's level on the improved performance of the students in the flipped sections. Table 3 summarizes the effects of the different factors on student results. The model showed overall significant differences $\left(F(3,248)=24.1, p<0.0001, \eta p^{2}=\right.$ $0.0753)$. Significant differences were found based on treatment (flipped vs. control, $\left.F(1,248)=39.1, p<0.0001, \eta p^{2}=0.1363\right)$ and Bloom's level of questions $(F(1,248)=$ 24.2, $\left.p<0.0001, \eta p^{2}=0.0889\right)$. The predicted overall effect of time (from post 1 to post 2) was not significant $(F(1,248)=$ $\left.0.0646, p=0.7996, \eta p^{2}=0.0003\right)$. These results were qualified by interactions between time and Bloom's level $(F(1,248)$ $\left.=4.21, p=0.0412, \eta p^{2}=0.0167\right)$ and between treatment and Bloom's level ( $F(1$, 248) $\left.=5.7, p=0.018, \eta p^{2}=0.02255\right)$. The interaction between time and Bloom's level 


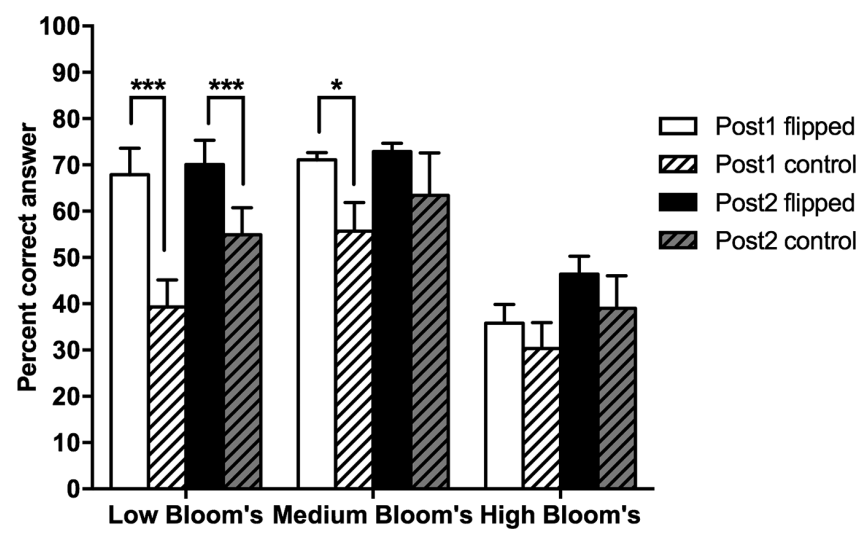

FIGURE 5. Percent of correct answers in the flipped and control sections, per Bloom's level of the questions. Significant differences were observed between flipped and control sections for the low-level Bloom's questions, both at post 1 and post $2(p<0.001)$. For medium-level Bloom's questions, the difference was significant only at post 1.

can be explained by students improving much more over time on low-level Bloom's questions. The interaction between Bloom's level and treatment appears to be explained mostly by low- and medium-level Bloom's questions. When answering low-level Bloom's questions, students in the flipped sections scored significantly higher than students in the control sections for both post 1 and post 2, but for medium-level Bloom's questions, that difference was only observed at post 1 , as discussed earlier.

\section{DISCUSSION}

Although the flipped-classroom method has been in use for more than 15 years, it still has no unified theoretical framework or methodology (Bishop and Verleger, 2013; Zuber, 2016), and it continues to present as widely varied implementations across educational settings and academic disciplines (Lage et al., 2000; Bishop and Verleger, 2013; Estes et al., 2014; Uzunboylu and Karagozlu, 2015; Zuber, 2016). However, it is accepted that most flipped settings feature video lectures watched outside the classroom, in-class activities, and limited lecturing during class time (Bishop and Verleger, 2013; Hamdan et al., 2013). Studies of flipped-classroom approach in accelerated courses have been rare. Francl (2014) described implementa-

TABLE 3. Repeated-measures ANOVA of matched student scores ${ }^{a}$

\begin{tabular}{lcccl}
\hline Test & $\boldsymbol{F}$ & $\boldsymbol{d} f$ & $\boldsymbol{p}$ value & \multicolumn{1}{c}{$\eta \mathbf{p}^{2}$} \\
\hline All between & 24.1 & 3,248 & $<0.0001$ & 0.0753 \\
Treatment & 39.1 & 1,248 & $<0.0001$ & 0.1363 \\
Bloom's & 24.2 & 1,248 & $<0.0001$ & 0.0889 \\
Treatment*Bloom's & 5.70 & 1,248 & 0.018 & 0.0225 \\
All within & 2.54 & 3,248 & 0.057 & 0.010 \\
Time & 0.065 & 1,248 & 0.7996 & 0.0003 \\
Time*treatment & 2.80 & 1,248 & 0.096 & 0.011 \\
Time*Bloom's & 4.21 & 1,248 & 0.0412 & 0.0167 \\
\hline
\end{tabular}

aFactors analyzed included treatment (flipped vs. control), Bloom's level of the questions, and time (post 1 vs. post 2). Significant differences were observed in the overall model, type of instruction (flipped vs. control), and Bloom's level of questions, but not in time (post 1 vs. post 2). tion of the flipped-classroom approach in two accelerated accounting/finance courses at the master's level (Francl, 2014), but did not present objective assessments. The flipped-classroom approach was found effective and scalable in a 5-week introductory spreadsheet course (Davies et al., 2013). To our knowledge, no flipped-classroom studies have been reported for accelerated biology courses.

Challenges to flipping the classroom are many and can be individual, institutional, technological or nontechnological (Gardner, 2015). The intensive nature of the NU course format, with its longer 4.5-hour class time, lends itself naturally to the flipped approach. The authors' goal was to create an intentional flipped-learning environment where, in addition to watching the prerecorded videos addressing specific concepts, students were involved in activities aligning with those same concepts in the classroom.

In addition, we were interested in how a predominantly nontraditional student population would respond to the change in course design. When minorities were grouped together, they made up $\sim 49-51 \%$ of the student population. Mean age was 29.41 and 29.93 in the flipped and control groups, respectively, highlighting the nontraditional nature of the student population.

When analyzing the results, several limitations should be considered. It is a common practice to have a pretest to compare students' previous knowledge in the experimental and control populations to guarantee it is comparable. Owing to the fast pace of the courses, having a pretest and the first posttest (addressing concepts such as biomolecules and cells, taught the first week of the course) with only 1 week of separation might have influenced students' answers, so no pretest was administered. While there were no significant differences between student demographics and GPA levels of the flipped and control sections, we cannot exclude that differences in previous knowledge may have influenced the results. Another limitation is that the instructors were different for the flipped and control sections. However, the number of years that each instructor has taught were similar (8-10 years), all had taught this general biology course before the study, and they followed the same CLOs and used the same textbook. Finally, our results did not reveal the in-class activities as a significant factor in the better results of the students in the flipped sections, so our study cannot answer the question as to what factor or factors were responsible for them. There have been conflicting results regarding to the reasons behind better student performance in the flipped setting, with some authors pointing to an increased course structure (Freeman et al., 2011), increased preclass preparation (Gross et al., 2015), active learning (Jensen et al., 2015), or even a more collaborative class climate (Strayer, 2012; Van Vliet et al., 2015).

Most students watched the videos, often multiple times, as evidenced by different measures from student self-reporting to analytics functions of both the media site and the course learning management system. In contrast to a previous study (Moravec et al., 2010), our students did not receive points to review these videos. However, they were told that the videos contained content that would be tested in class, which may have constituted enough motivation for students to review them. 
In the present study, students in the flipped sections correctly answered significantly more questions compared with the students in the control sections, both after the material was covered (post 1) and at the end of the course (post 2). Because of the nature of the accelerated format, with in-class sessions of more than 4 hours in length, a pure lecture-based format is untenable. While students in the control sections did not have access to the recorded lectures, the instructors did include YouTube and publisher-provided videos during class time and conducted an in-class activity corresponding to a LO not included in this study. Therefore, the significantly higher scores of the students in the flipped sections are even more noteworthy. Interestingly, the quiz scores of students in the control sections approached those of the flipped sections by post 2 . The overall improvement may be due to students remembering the quiz questions, because the same questions were asked in post 1 and post 2 . Another possibility is that, with time in class, control students became more comfortable with the material, especially as the concepts corresponding to LO1 and LO2 are the basis of subsequent material of the later weeks of the course. Upon closer examination, the gain in quiz scores of students in the control sections was due to a significant improvement in the questions corresponding to LO2 (cellular structure and processes). A possible explanation for this difference could be that students revisited LO2 concepts more often than LO1 concepts in the later portion of the course, and thus even control students did better in these questions when post 2 was administered.

Driven by the number of variables assessed in this study (flipping, timing of the quizzes, different Bloom's taxonomy level of the quiz questions, as well as the presence and complexity of in-class activities), we decided to evaluate the variables using AIC scores to determine the most appropriate model. Overall, type of instruction (flipped vs. control) and the Bloom's level of the questions emerged as the significant variables of the study.

Regarding the Bloom's score of questions, students in the flipped section answered more questions correctly at all three levels. Interestingly, the only statistical difference between flipped and control students at both post 1 and post 2 time points was observed for the lowest-level Bloom's questions. As our original goal was to support students' higher-order Bloom's skills, this result was disappointing. However, considering that this course is students' first encounter with biology material, the fact that students in the flipped sections would benefit mainly through improving lower-level learning skills is in and of itself not a negative. It has been reported that introductory biology students learn more vocabulary words than students taking an introductory foreign language course (Bravo and Cervetti, 2008), and for many students, remembering the many new scientific terms can be a major hurdle (diSessa, 1993; Chi, 2005). In addition, one study found that active learning by itself did not correlate to better student learning of a more advanced concept such as natural selection. Improved learning of new biological concepts by repeatedly watching recorded lectures and reinforcement of this learning through in-class activities may in turn result in higher student retention during the challenging introductory science courses (Andrews, et al., 2011).

It is also noteworthy that student scores in the flipped sections were similar for post 1 and post 2 , showing a lasting effect of the material learned at the very beginning of the course. It might be the case that having access to the recorded materials outside the class, in addition to a dynamic classroom environment early on, helped students to cement their learning of basic concepts. Students in accelerated courses require organization to facilitate learning and welcome active, creative approaches in the classroom (Scott, 2003). Moreover, freed from the requirement of extensive lecturing, instructors in flipped classrooms are able to dedicate more time not only to implement active learning, but also, if class size allows, for more direct interactions with students.

AIC scores indicated that activities did not have a significant effect on quiz scores. This result did not support our third hypothesis, which was based on studies that attributed the gains of the flipped approach to the use of active learning (Jensen et al., 2015) irrespective of time devoted to it in the classroom (Adams et al., 2016). In fact, our course design intentionally aligned more difficult concepts with higher-impact activities. However, an extensive analysis of active-learning practices among randomly selected college instructors showed no effect of high-impact activities when evaluating students' understanding of advanced concepts (Andrews et al., 2011). Moreover, our results may support a previous study that claimed students in flipped classrooms do better than their control counterparts because of increased preclass preparation (Gross et al., 2015). Thus, the experimental design encouraging students to watch the learning videos early on due to the post 1 quiz (as a required test) may have provided a more structured learning environment. Other studies have shown this to be beneficial in general (Freeman et al., 2011; Haak et al., 2011) and to disproportionately help certain demographic populations such as Blacks/African Americans, Hispanics, or first-generation college students (Quitadamo and Kurtz, 2007; Eddy and Hogan, 2014).

In general, students in our study overwhelmingly expressed their approval of hands-on active-learning practices in the classroom. As one student stated in the official end-of-class survey: "Great great [sic] class!! This professor provided hands-on material for us to interact not just with each other but with the subject." However, other aspects need to considered when evaluating the importance of the in-class activities. Chi (2009) described a framework to differentiate learning activities based on underlying learning processes, which may provide additional criteria to how activities are selected and classified. Their model classifies activities in three types: active, constructive, and interactive, based on the cognitive processes underlying each type (Chi, 2009). A closer examination of the in-class activities used in this study could help explain why their use was not a significant factor in students' improved scores in the flipped sections.

Our study focused on a nontraditional student population: older and with a higher proportion of minorities. Active-learning pedagogy has been shown to enhance URM students' selfefficacy and feeling of classroom social belonging, which in turn decreases the achievement gap between URM and non-URM students (Ballen et al., 2017). A similar effect of active learning reducing the biology learning gap was observed when comparing students from educationally or economically disadvantaged backgrounds (EOP)—who are overwhelmingly URM-and non-EOP students (Haak et al., 2011). In a 2014 New Media 
Consortium report, the flipped-classroom methodology was listed as one of the digital strategies in higher education that could "transcend conventional ideas and learning activities to create something that is new, meaningful, and 21st century" (Johnson et al., 2014, p. 34). This may be particularly useful for nontraditional students, as adult learners have been described as technologically savvy (Wlodkowski, 2017). Be it through a more structured course design, more preclass study time, a better sense of community, acquisition of better study skills, or a combination thereof, active learning facilitated by a flipped setting seems a straightforward approach to enhance student success in the introductory biology classroom.

As nontraditional students, adult learners come to the classroom with their life experiences, which provide a rich supply of resources for the learning process, but may also constitute a barrier due to misconceptions and incorrect mental habits (Knowles et al., 2015). As we move forward with the expansion of the flipped approach to all sections of this course, we are exploring the reasons for the improvement limited to lower-level cognitive skills. In an ongoing study, we use a thinkaloud strategy to explore how students apply biology concepts to higher-level Bloom's open-ended questions. Preliminary results of students' verbalized analytic processes often show the existence of misconceptions and a reliance on memorized information. A better understanding of students' difficulties will help to optimize the activities deployed in the classroom.

Because of current adult learners' vast variety of beliefs, perspectives, incomes, experiences, and histories, there is no one way to address their educational needs. A flipped-classroom environment with in-class active learning is just one of many ways instructors could facilitate student learning by supporting the acquisition of knowledge using optimal approaches at each step of the way.

\section{ACKNOWLEDGMENTS}

We thank Dean Carol Richardson for her support of this project through internal grants, Charles Tatum for help with assessment design, and Mike Kirkpatrick for help with statistical methodology. We also thank the ASM Biology Scholars Research Residency 2015 Cohort instructors and participants for valuable feedback and advice of the project. This project would not have been possible without the help of Michael Maxwell, Goran Bozinovic, Nima Salimi, and Gregory Borman.

\section{REFERENCES}

Abeysekera, L., \& Dawson, P. (2014). Motivation and cognitive load in the flipped classroom: Definition, rationale and a call for research. Higher Education Research \& Development, 34(1), 1-14. https://doi.org/10.1080/ 07294360.2014 .934336

Adams, A. E. M., Garcia, J., \& Traustadóttir, T. (2016). A quasi experiment to determine the effectiveness of a partially flipped versus fully flipped undergraduate class in genetics and evolution. CBE-Life Sciences Education, 15(2), ar11. https://doi.org/10.1187/cbe.15-07-0157

American Association for the Advancement of Science (AAAS). (2011). Vision and change in undergraduate biology education: A call to action. Washington, DC.

AAAS. (2015). Vision and change in undergraduate biology education: Chronicling change, inspiring the future. Washington, DC.

Anderson, L. W., Krathwohl, D. R. D. R., \& Bloom, B. S. (2001). A taxonomy for learning, teaching, and assessing: A revision of Bloom's taxonomy of educational objectives. New York: Longman. https://doi.org/10.1207/ s15430421tip4104_2
Andrews, T. M., Leonard, M. J., Colgrove, C. A., \& Kalinowski, S. T. (2011). Active learning not associated with student learning in a random sample of college biology courses. CBE-Life Sciences Education, 10(4), 394405. https://doi.org/10.1187/cbe.11-07-0061

Arnott, J. A., \& Planey, S. L. (2017). Flipped classroom approaches lead to no improvement in learning outcomes or student perceptions. FASEB Journal, 31, 751.14-751.14.

Aslanian, C. B. (2017). Post-traditional college students: Attracting and serving the new majority. Retrieved June 20, 2017, from https://learn .educationdynamics.com/post-traditional-students-report

Ballen, C. J., Wieman, C., Salehi, S., Searle, J. B., \& Zamudio, K. R. (2017) Enhancing diversity in undergraduate science: Self-efficacy drives performance gains with active learning. CBE-Life Sciences Education, 16(4), ar56. https://doi.org/10.1187/cbe.16-12-0344

Baun, J. T. (2008). A comparison of learning and retention between students taught in a traditional versus an accelerated format over four months in a clinical legal trial advocacy course: A quantitative evaluation study. Proquest Dissertations and Theses. University of NebraskaLincoln. Retrieved from https://search.proquest.com/docview/ 304519697 ? accountid $=25320$

Bishop, J. L., \& Verleger, M. A. (2013). The flipped classroom: A survey of the research. In ASEE National Conference Proceedings (Vol. 30, No. 9, pp. 1-18).

Bradforth, S. E., Miller, E. R., Dichtel, W. R., Leibovich, A. K., Feig, A. L., Martin, J. D., ... Smith, T. L. (2015). University learning: Improve undergraduate science education. Nature, 523(7560), 282-284. https://doi.org/10.1038/ $523282 a$

Bravo, M. A., \& Cervetti, G. N. (2008). Teaching vocabulary through text and experience in content areas. In Farstrup, A. E., \& Samuels, S. J. (Eds.), What research has to say about vocabulary instruction (pp. 130-149). Newark, DE: International Reading Association.

Chen, X., \& Soldner, M. (2013). STEM attrition: College students' paths into and out of STEM fields (NCES 2014-001). Washington, DC: National Center for Education Statistics.

Chi, M. T. H. (2005). Commonsense conceptions of emergent processes: Why some misconceptions are robust. Journal of the Learning Sciences, 14(2), 161-199. https://doi.org/10.1207/s15327809jls1402_1

Chi, M. T. H. (2009). Active-constructive-interactive: A conceptual framework for differentiating learning activities. Topics in Cognitive Science, 1(1), 73-105. https://doi.org/10.1111/j.1756-8765.2008.01005.x

Choy, S. (2002). Findings from the Condition of Education 2002: Nontraditional undergraduates. Washington, DC: National Center for Education Statistics.

College Board. (2017). National University page. Retrieved June 20, 2017, from https://bigfuture.collegeboard.org/college-university-search/national -university

Crowe, A., Dirks, C., \& Wenderoth, M. P. (2008). Biology in Bloom: Implementing Bloom's taxonomy to enhance student learning in biology. CBE-Life Sciences Education, 7(4), 368-381.

D'Avanzo, C. (2013). Post-Visionand Change: Do we know how to change? CBE-Life Sciences Education, 12(3), 373-382.

Davies, R. S., Dean, D. L., \& Ball, N. (2013). Flipping the classroom and instructional technology integration in a college-level information systems spreadsheet course. Educational Technology Research and Development, 61(4), 563-580. https://doi.org/10.1007/s11423-013-9305-6

Dirks, C., \& Knight, J. K. (2016). Measuring college learning in biology. In Arum, R., Roksa, J., \& Cook, A. (Eds.), Improving quality in American higher education: Learning outcomes and assessments for the 21st century (pp. 225-260). San Francisco: Jossey-Bass.

diSessa, A. A. (1993). Toward an epistemology of physics. Cognition and Instruction, 10(2-3), 105-225. https://doi.org/10.1080/07370008.1985 9649008

Dolan, E. L. (2015). Biology education research 2.0. CBE-Life Sciences Education, 14(4), ed1.

Eddy, S. L., Converse, M., \& Wenderoth, M. P. (2015). PORTAAL: A classroom observation tool assessing evidence-based teaching practices for active learning in large science, technology, engineering, and mathematics 
classes. CBE-Life Sciences Education, 14(2), ar23. https://doi.org/ 10.1187/cbe.14-06-0095

Eddy, S. L., \& Hogan, K. A. (2014). Getting under the hood: How and for whom does increasing course structure work? CBE-Life Sciences Education, 13(3), 453-468.

Estes, M. D., Ingram, R., \& Liu, J. C. (2014). A review of flipped classroom research, practice, and technologies. International HETL Review, 4(7).

Estrada, M., Burnett, M., Campbell, A. G., Campbell, P. B., Denetclaw, W. F., Guti?rrez, C. G., ... Zavala, M. E. (2016). Improving underrepresented minority student persistence in stem. CBE-Life Sciences Education, 15(3), es5. https://doi.org/10.1187/cbe.16-01-0038

Flipped Learning Network. (2014). What Is Flipped Learning? The Four Pillars of F-L-I-P. FLIP Learning. Retrieved June 25, 2018, from https:// flippedlearning.org/

Francl, T. J. (2014). Is flipped learning appropriate? Journal of Research on Innovative Teaching, 7(1), 119-129. https://doi.org/doi.org.proxy2.lib .umanitoba.ca/10.1

Freeman, S., Eddy, S. L., McDonough, M., Smith, M. K., Okoroafor, N., Jordt H., \& Wenderoth, M. P. (2014). Active learning increases student performance in science, engineering, and mathematics. Proceedings of the National Academy of Sciences USA, 111(23), 8410-8415.

Freeman, S., Haak, D., \& Wenderoth, M. P. (2011). Increased course structure improves performance in introductory biology. CBE-Life Sciences Education, 10(2), 175-186

Freeman, S., O'Connor, E., Parks, J. W., Cunningham, M., Hurley, D., Haak, D. ... Wenderoth, M. P. (2007). Prescribed active learning increases performance in introductory biology. CBE-Life Sciences Education, 6(2), 132 139. https://doi.org/10.1187/cbe.06-09-0194

Gardner, J. (2015). Flipping the classroom: Challenges of implementation. In Scheg, A. G. (Ed.), Implementation and critical assessment of the flipped classroom experience (pp. 157-174). Hershey, PA: IGI Global. https://doi .org/10.4018/978-1-4666-7464-6.ch009

Gross, D., Pietri, E. S., Anderson, G., Moyano-Camihort, K., \& Graham, M. J. (2015). Increased preclass preparation underlies student outcome improvement in the flipped classroom. CBE-Life Sciences Education 14(4), ar36. https://doi.org/10.1187/cbe.15-02-0040

Haak, D. C. D. C., HilleRisLambers, J., Pitre, E., \& Freeman, S. (2011). Increased structure and active learning reduce the achievement gap in introductory biology. Science, 332(6034), 1213-1216.

Hamdan, N., McKnight, P., McKnight, K., \& Arfstrom, K. M. (2013). The Flipped Learning Model: A White Paper Based on the Literature Review Titled a Review of Flipped Learning. FLIP Learning. Retrieved June 25, 2018, from https://flippedlearning.org/wp-content/uploads/2016/07/WhitePaper _FlippedLearning.pdf

Handelsman, J., Miller, S., \& Pfund, C. (2007). Scientific teaching. New York: Freeman.

Hispanic Association of Colleges and Universities-HACU. (n.d.). Home page. Retrieved June 20, 2017, from www.hacu.net/assnfe/cv.asp?ID=159

James, S. M., \& Singer, S. R. (2016). From the NSF: The National Science Foundation's investments in broadening participation in science, technology, engineering, and mathematics education through research and capacity building. CBE-Life Sciences Education, 15(3), fe7. https://doi. org/10.1187/cbe.16-01-0059

Jensen, J. L., Kummer, T. A., \& d M Godoy, P. D. (2015). Improvements from a flipped classroom may simply be the fruits of active learning. CBE-Life Sciences Education, 14(1), ar5. https://doi.org/10.1187/cbe.14-08-0129

Johnson, L., Becker, S., Estrada, V., \& Freeman, A. (2014). NMC horizon report: 2014 higher education. Austin, TX: New Media Consortium. https:// doi.org/10.1086/529497

Jordt, H., Eddy, S. L., Brazil, R., Lau, I., Mann, C., Brownell, S. E., ... Freeman, S. (2017). Values affirmation intervention reduces achievement gap between underrepresented minority and white students in introductory biology classes. CBE-Life Sciences Education, 16(3), ar41. https://doi org/10.1187/cbe.16-12-0351
Knowles, M. S., Holton, E. F. I., \& Swanson, R. A. (2015). The adult learner: The definitive classic in adult education and human (8th ed.). New York: Taylor and Francis

Lage, M. M. J., Platt, G. G. J., \& Treglia, M. (2000). Inverting the classroom: A gateway to creating an inclusive learning environment. Journal of Economic Education, 31(1), 30-43. https://doi.org/10.1080/00220480009596759

McGlynn, T. P. (2017). Identity matters: Communicating about equity and opportunity for students in minority-serving institutions. Annals of the Entomological Society of America, 110(5), 480-483. https://doi.org/ 10.1093/aesa/sax050

Moravec, M., Williams, A., Aguilar-Roca, N., \& O'Dowd, D. K. (2010). Learn before lecture: A strategy that improves learning outcomes in a large introductory biology class. CBE-Life Sciences Education, 9(4), 473-481. https://doi.org/10.1187/cbe.10-04-0063

President's Council of Advisors on Science and Technology. (2012). Engage to excel: Producing one million additional college graduates with degrees in science, technology, engineering, and mathematics. Washington, DC: U.S. Government Office of Science and Technology.

Quitadamo, I. J., \& Kurtz, M. J. (2007). Learning to improve: Using writing to increase critical thinking performance in general education biology. CBE-Life Sciences Education, 6(2), 140-154. https://doi.org/10.1187/ cbe.06-11-0203

Radford, A. W., Cominole, M., \& Skomsvold, P. (2015). Demographic and enrollment characteristics of nontraditional undergraduates: 2011-12. Washington, DC: National Center for Education Statistics.

Schinske, J. N., Balke, V. L., Bangera, M. G., Bonney, K. M., Brownell, S. E., Carter, R. S., ... Corwin, L. A. (2017). Broadening participation in biology education research: Engaging community college students and faculty. CBE-Life Sciences Education, 16(2), mr1. https://doi.org/10.1187/cbe.16-10-0289

Scott, P. A. (2003). Attributes of high-quality intensive courses. New Directions for Adult and Continuing Education, 2003(97), 29-38.

Shaffer, C. D., Alvarez, C. J., Bednarski, A. E., Dunbar, D., Goodman, A. L., Reinke, C., ... Elgin, S. C. R. (2014). A course-based research experience: How benefits change with increased investment in instructional time. CBE-Life Sciences Education, 13(1), 111-130. https://doi.org/10.1187/ cbe-13-08-0152

Stains, M., Harshman, J., Barker, M. K., Chasteen, S. V., Cole, R., DeChenne-Peters, S. E., ... Young, A. M. (2018). Anatomy of STEM teaching in North American universities. Science, 359(6383), 1468-1470. https://doi .org/10.1126/science.aap8892

Strayer, J. F. (2011). The flipped classroom: Turning the traditional classroom on its head. Knewton. Retrieved June 25, 2018, from www knewton.com/flipped-classroom/

Strayer, J. F. (2012). How learning in an inverted classroom influences cooperation, innovation and task orientation. Learning Environments Research, 15, 171-193. https://doi.org/10.1007/s10984-012-9108-4

Uzunboylu, H., \& Karagozlu, D. (2015). Flipped classroom: A review of recent literature. World Journal on Educational Technology, 7(2), 142. https:// doi.org/10.18844/wjet.v7i2.46

Van Vliet, E. A., Winnips, J. C., \& Brouwer, N. (2015). Flipped-class pedagogy enhances student metacognition and collaborative-learning strategies in higher education but effect does not persist. CBE-Life Sciences Education, 14(3), ar26. https://doi.org/10.1187/cbe.14-09-0141

Wlodkowski, R. J. (2017). Enhancing adult motivation to learn: A comprehensive guide for teaching all adults. San Francisco, CA: Wiley.

Wlodkowski, R. J., \& Kasworm, C. E. (2003). Accelerated learning: Future roles and influences. New Directions for Adult and Continuing Education, 2003(97), 5-16. https://doi.org/10.1002/ace.92

Yong, D., Levy, R., \& Lape, N. (2015). Why no difference? A controlled flipped classroom study for an introductory differential equations course. Primus, 25(9-10), 907-921. https://doi.org/10.1080/10511970.2015.1031307

Zuber, W. J. (2016). The flipped classroom, a review of the literature. Industrial and Commercial Training, 48(2), 97-103. https://doi.org/10.1108/ ICT-05-2015-0039 